\title{
A Study on Comparative Antioxidant Properties of Mimosa pudica, Vachellia nilotica, Leucas aspera, Phyllanthus niruri, Emidesmus indicus and Adhatoda vasica
}

\author{
Srishti Prashar ${ }^{1}$, Parminder Kaur ${ }^{2}$, Prakriti Sharma ${ }^{2}$, \\ Arshida Khatun ${ }^{2}$ and Nasrul I. Shaikh ${ }^{1^{*}}$
}
${ }^{1}$ College of Animal Biotechnology, Guru Angad Dev Veterinary and Animal Sciences University, Ludhiana, Punjab, India
${ }^{2}$ Sri Guru Nanak Dev Homoeopathic Medical College and Hospital, Ludhiana, India *Corresponding author

\section{A B S T R A C T}

\begin{tabular}{|l|}
\hline Ke y w o r d s \\
Antioxidants, \\
Mimosa pudica, \\
Vachellia nilotica \\
\hline Article Info \\
\hline $\begin{array}{l}\text { Accepted: } \\
\text { 07 November } 2020 \\
\text { Available Online: } \\
\text { 10 December } 2020\end{array}$ \\
\hline
\end{tabular}

Antioxidants reduce the risk of many diseases, including certain cancer and cardiovascular diseases. Medicinal plants can be a promising source of essential antioxidants due to the presence of phytochemicals such as flavonoids, phenolic compounds. In these present paper comparative antioxidant properties of Mimosa pudica, Vachellia nilotica, Leucas aspera, Phyllanthus Niruri, Hemidesmus indicus and Adhatoda vasica has been studied. The total phenolic content, total flavonoid assay, DDPH Radical Scavenging activity, ABTS Scavenging activityand Nitric Oxide Scavenging Assay evaluated. Results showed that among the plants, Adhatoda vasica possessed high antioxidant potential followed by Phyllanthus niruri and Leucas aspera.

\section{Introduction}

In the recent years, medicinal plants have gained significant attention due to their pharmaceutical properties. There are a huge number of medicinal plants, which are being explored for its pharmaceutical applications such as Mimosa pudica, Vachellia nilotica, Leucas aspera, Phyllanthus niruri, Hemidesmus indicus and Adhatoda vasica.

Mimosa pudica (MP) is an annual/perennial herb which is also known as touch me not. It is a native plant of South America and central America, but now it has turned into a common weed around the world (Varnika et $a l ., 2012)$. It is a young plant which reaches up to the height of $1.5 \mathrm{~m}(5 \mathrm{ft})$ with erect stems that bears bipinnately compound leaves with 10 to 30 leaflets per pinna and pink or purple colored globular flowers having 8-10 mm diameter(Miller et al., 2012). The roots of this plant are used for the treatment of inflammation, asthma, dysentery, leprosy, burning sensation, piles, jaundice, bilious fevers and tooth ache, skin diseases. It is the main ingredient in herbal preparation for gynecological disorders (Joseph et al., 2013, Ahmad et al., 2012). It stops bleeding and fastens the wound healing process alongside 
treating diarrhea, amoebic dysentery, bleeding piles and urinary infections (Varnika et al., 2012). It is also beneficial for treatment of bronchitis, general weakness and impotency. Recent evidence depicts that Mimosa pudica have the ability to cure psychological disorders like depression, mental distress, irritability, severe palpitations (Keerthi Kanimozhi, 2017; Patro et al., 2016). It is due to its property of healthy cell growth, is used in shampoos, creams, capsules and soaps (Joseph et al., 2013). It contains a large number of phytochemicals such as alkaloid mimosine, responsible for its antiproliferative and apoptotic properties flavonoid cglycosides, sterols, tannin, terpenoids and fatty acids (Mahanta et al., 2001).

Vachellia nilotica (VN), commonly known as babul, is native to Egypt but also found across Maghreb and Sahel, America, South Africa, Arabian Peninsula, Pakistan, India and Burma(Ahmad et al., 2012). A Greek botanist-physician Pedanius Dioscorides has also discussed about this plant in his book Materia medica. It is a tree which reaches up to 5-20 $\mathrm{m}$ in height with a dense crown, stems and branches usually dark to black coloured. It has thin, straight, light, grey spines in axillary pairs (3 to 12 pairs), 5 to 7.5 $\mathrm{cm}$ long in young trees whereas mature trees are commonly found without thorns.

The leaves of this plant are bipinnate, with 3 6 pairs of pinnulae and 10-30 pairs of leaflets each. Although, flowers having 1.2-1.5 cm in diameter and are of bright golden-yellow colors, which are located on globulus heads. Furthermore, pods are strongly constricted, hairy, white-grey and thick with approximately 8000/kg seeds (Ahmad et al., 2012) Furthermore, the tender twig of this plant is used as tooth brush and the gum is used in manufacture of medicines, dyes and paint (Singh, 2015).
Leucas aspera (LA), commonly known as thumbai, belongs to the family of Labiatae, is a common aromatic herb found as weed in Africa, Asia-temperate and Asia-tropical countries (Chew et al., 2012) whereas in India it is mainly found from Himalayas to Ceylon in waste places (Prajapati et al., 2010; Jayakumar et al., 2015). Traditionally, the whole plant is taken orally for treatment of analgesic, antipyretic, antirheumatic, antiinflammatory and antibacterial activities (Chew et al., 2012; Goudgaon et al., 2003). Plant is also used as medicine for cough, cold, painful swelling and chronic skin eruption (Rahman et al., 2013). Leaves of L. aspera are useful in chronic rheumatisim, psoriasis, skin eruptions (Chew et al., 2012). A study evaluated that methanol extracts of various parts of L. aspera for biologic activity showed that methanol extracts of root showed antioxidant activity near the range of vitamin E. Moreover, a significant antibacterial activity is shown by crude extracts of root, flower, leaf and stem (Chew et al., 2012).

Phyllanthus niruri (PN) is a common herb of central and southern India but its species are also found in other countries, including China, the Philippines, Cuba, Nigeria, and Guam. It grows up to $60 \mathrm{~cm}$ in height and blooms with many yellow flowers. All parts of the plant are employed therapeutically (Ezzat et al., 2020). Phyllanthus has been used in Ayurvedic medicine since 2,000 years and has a wide number of traditional uses such as in treatment of jaundice, gonorrhea, frequent menstruation and diabetes. Along with that, it is also used topically as a poultice for skin ulcers, sores, swelling, and itchiness. It is very effective for clearing gall- bladder stones. The young shoots of the plant are administered in the form of an infusion for the treatment of chronic dysentery (Joseph et al., 2011). The Phytochemical analysis of Phyllanthus niruri revealed that it contains lignins, alkaloids, and bioflavonoids (Naik et al., 2003). 
Hemidesmus indicus (HI), commonly known as Indian sarsaparilla, which belongs to the family asclepiadaceous. It is a perennial climber which grows widely in upper gangetic plains, East Bengal and from Central to South India (Dandekar et al., 2008). The Woody portions of the plant are used traditionally for curing various ailments like stomach pain, fever, veneral diseases, skin diseases, urinary infections, rheumatism, leprosy, impotence, nutritional disorders, syphilis, gravel, act as the blood purifier (Das et al., 2017, Pansare et al., 2018) and also serve as an alternative tonic, demulcent, diaphoretic whereas, the roots have $\mathrm{p}$ methoxy salicylic aldehyde as a main component which is used substantially by native of Orissa state (India) for curing diarrhea and dysentery (Aneja et al., 2008). Moreover, roots of plant possess anti venom property as an organic acid, isolated and purified from its root extract to possess inhibitory activity against viper venom.

Results obtained from experiments conducted by Gupta and Peshin (2012) revealed that the isolated compound remarkably antagonized viper venom-induced lethal, hemorrhagic, coagulant and anticoagulant activity in rodents. Furthermore, root extracts are also used as the blood purifier (Gupta and Peshin, 2012) whereas, various effects of the plant, including hypoglycemic, hypolipidemic, antioxidant, antithrombotic, antiinflammatory, antiulcerogenic, hepatoprotective, renoprotective, and neutralization of viper venom has also been reported.

Adhatoda vasica (AV) which is also known as vasaka is distributed throughout India up to an altitude of $1300 \mathrm{~m}$. Manisha (2019) reported that the leaves, flowers, fruit, and roots of this plant are widely used in treatment of cold, cough, whooping cough, arthritis, diarrhea, dysentery, chronic bronchitis and asthma as sedative and antispasmodic. The parts of this plant are also used as most potent antituberculosis drugs as well as vasicine (Sheeba and Mohan, 2012). The aim of the present study is to compare the phytochemicals and antioxidant potential of Mimosa pudica, Vachellia nilotica, Leucas aspera, Phyllanthus niruri, Hemidesmus indicus and Adhatoda vasica, in order to assign the plants an appropriate ranking based on their phytochemical content and their antioxidant potential.

\section{Materials and Methods}

\section{Sample collection and preparation of samples}

Leaves of the plants were collected from Sri Guru Nanak Dev Homoeopathic Medical college and Hospital, Ludhiana. The leaves are cleaned to remove any dust before air drying at room temperature under a shaded roof. Leafs were powdered to obtain $30 \mathrm{~g}$ of leaf powder and extracted to exhaustion in a soxhlet apparatus with methanol, which is then allowed to run for three days. The extract was collected and subjected to dryness under stable temperature of $40-50^{\circ} \mathrm{C}$.

\section{Total phenolic content}

Extract were prepared at concentration of 25, 50, 100 and $200 \mu \mathrm{g} / \mathrm{ml}$ and absorbance for each concentration of extracts was recorded. Furthermore, the total phenolic content of samples was measured following the method reported by Mallick et al., (1980). Different samples were taken and mixed with $0.5 \mathrm{ml}$ of Folin-ciocalteau reagent $(0.2 \mathrm{~N})$. After $5 \mathrm{~min}$ $2 \mathrm{ml}$ of sodium carbonate $(20 \%)$ was added and then incubated for 60 minutes at room temperature. The absorbance was measured at $765 \mathrm{~nm}$. The standard curve was obtained using gallic acid as standard at a concentration $10-50 \mu \mathrm{g} / \mathrm{mL}$. The total phenolic content was expressed as gallic acid equivalents (GAE) mg/g dry weight. 


\section{Total flavonoid assay}

Total flavonoids content was calculated by method described by Kim et al (2002). Quercetin at a concentration of $25 \mu 1-100 \mu 1$ was used as standard to construct a calibration curve (absorbance vs. $\mu \mathrm{g} / \mathrm{mL}$ quercetin). $0.5 \mathrm{ml}$ of extracts was mixed with $1.5 \mathrm{ml}$ of methanol, $0.1 \mathrm{ml}$ of $10 \%$ aluminum chloride, $0.1 \mathrm{ml}$ of $1 \mathrm{M}$ potassium acetate, and $2.8 \mathrm{ml}$ of distilled water. The solution was incubated at $37^{\circ} \mathrm{C}$ for 30 minutes. The absorbance of mixture was measured at $415 \mathrm{~nm}$. Total flavonoid content was expressed as $\mathrm{mg}$ quercetin equivalents $(\mathrm{QE}) / \mathrm{g}$ dry weight.

\section{DPPH Radical Scavenging activity}

The DPPH radicals scavenging activity of plants was assessed according to the method developed by Atoui et al., (2005). Different plants extracts were added to $0.3 \mathrm{mM}$ solution of DPPH solution $(11 \mathrm{mg}$ of DPPH in $50 \mathrm{ml}$ of methanol). After 30 minutes of incubation, the discoloration of the purple to yellow color was observed and absorbance was measured at $520 \mathrm{~nm}$. Methanol was used as blank and DPPH solution was taken as positive control. The percentage of inhibition was calculated as AA $(\%)=($ Control absorbance - Sample absorbance) / Control absorbance $\times 100$.

\section{ABTS scavenging activity}

Scavenging ability of plant samples on ABTS was measured according to the method reported by $\operatorname{Re}$ et al., (1999). The radical cation was prepared by mixing $7 \mathrm{mM}$ ABTS stock solution with $2.4 \mathrm{mM}$ sodium persulfate in equal (1:1) ratio and mixture was kept overnight in dark at room temperature until the reaction is complete. The optical density (OD) of ABTS solution was set between 0.81 by diluted with $50 \%$ methanol. Different plant extracts were added to every $2 \mathrm{ml}$ of ABTS solution. After 30 minutes of incubation, absorbance of all samples was taken at $745 \mathrm{~nm}$. The antioxidant activity (AA) of the test samples were calculated by determining the decrease in absorbance, using the following equation:

AA $(\%)=($ Control absorbance - Sample absorbance) / Control absorbance $\times 100$

\section{Nitric oxide scavenging assay}

Nitric oxide scavenging activity was studied following the method described by Shirwaikar et al., (2006).The principle of this assay is based on the generation of nitric oxide from sodium nitroprusside and their interaction with oxygen to produce nitrite ions. The scavenger of nitric oxide competes with oxygen and lead to the reduced production of nitrite ion. For the estimation, different plant extracts $(50 \mu \mathrm{l})$ dissolved in phosphate buffer (1M. pH7.4) is incubated with $2 \mathrm{ml}$ of Sodium nitroprusside $(10 \mathrm{mM})$ in $0.9 \mathrm{ml}$ standard phosphate buffer at $37^{\circ} \mathrm{C}$ for 30 minutes. After incubation, $0.5 \mathrm{ml}$ griess reagent $(1 \%$ sulphanilamide, 2\% O-phosphoric acid and $0.1 \%$ NEDA) was added. The absorbance of chromophore formed during diazotization of nitrite with sulphanilamide and its subsequent coupling with napthyl ethylene diamine showed pink colour. The absorbance was taken at $546 \mathrm{~nm}$.Phosphate buffer saline was taken as blank. The Nitric oxide scavenged was estimated using following formula.

$\%$ scavenging activity $=\left[\mathrm{A}_{546}\right.$ (control) $-\mathrm{A}_{546}$ (sample) $] / \mathrm{A}_{546}$ (control) $\times 100$.

\section{Results and Discussion}

The objective of current research was to compare the total polyphenols content (TPC) and Total flavonoid content (TFC) of Mimosa Pudica, Vachellia Nilotica, Leucas Aspera and Phyllanthus Niruri. Furthermore, to evaluate the antioxidant potential of the same, 
were examined for its DPPH, ABTS and NO induced reactive oxygen species scavenging activity. The total phenolic content (TPC) of Adhatoda vesica was found to be higher (129.83mg GAE per g) followed by Phyllanthus niruri (121.3mg GAE per g),
Leucas aspera (120.7mg GAE per g), Mimosa pudica (118.8mg GAE per g), Hemidesmus indicus (115.8mg GAE per g) and Vachellia nilotica (114.2mg GAE per g) as depicted in Fig.1(a).

Fig.1 (a) The total phenolic content (TPC) of different plant extracts (b) The total flavonoids content (TPC) of different plant extracts Results represent the mean $\operatorname{SD}(n=3)$ and * on the bars denote the significant difference $(\mathrm{P} \leq 0.05)$

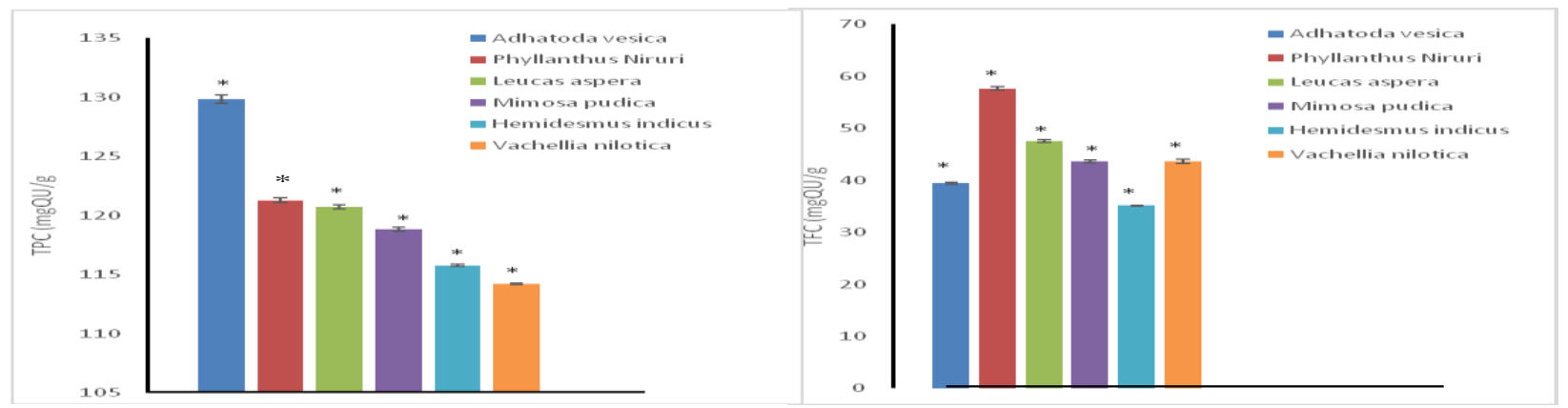

Fig.2 DPPH scavenging activity of different plants. Results represent the mean $\operatorname{SD}(\mathrm{n}=3)$ and * on the bars denote the significant difference within the plants $(\mathrm{P} \leq 0.05)$

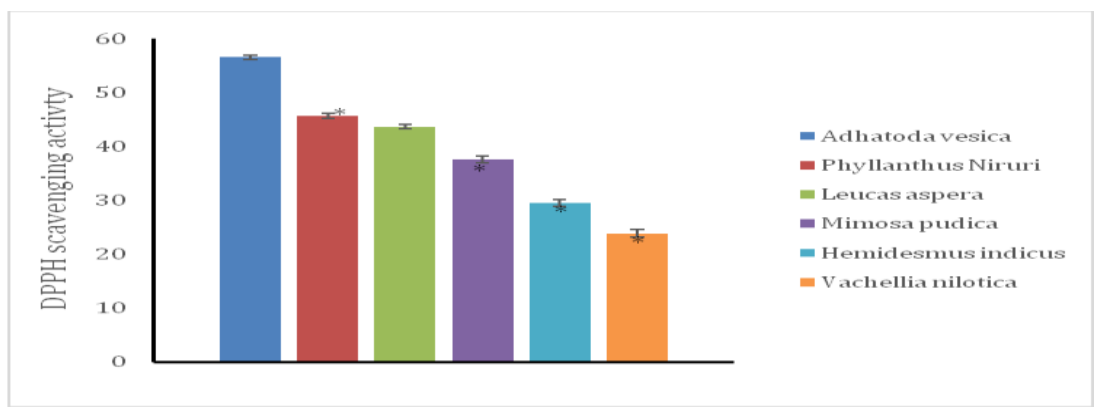

Fig.3 Nitric oxide scavenging activity of different plants. Results represent the mean $\operatorname{SD}(n=3)$ and $*$ on the bars denote the significant difference within the plants $(\mathrm{P} \leq 0.05)$

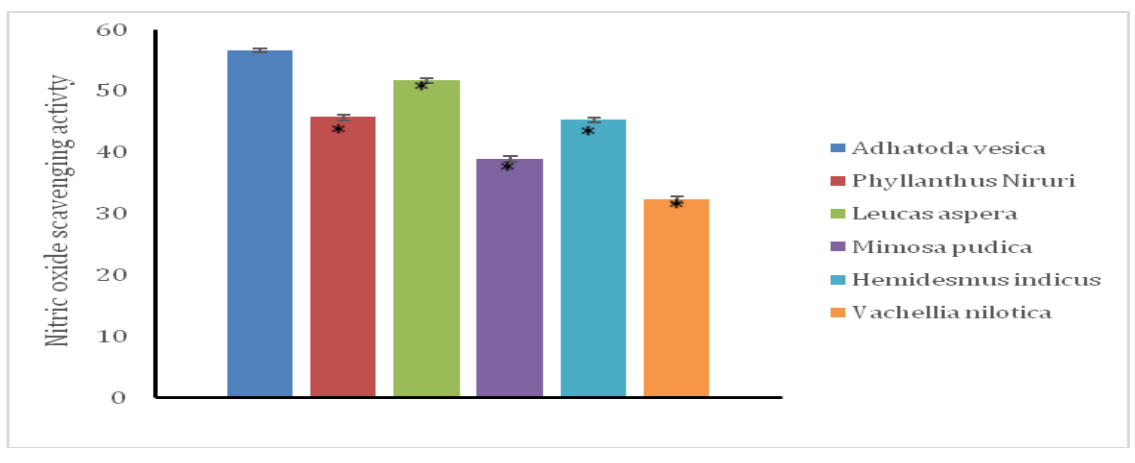


Fig.4 ABTS free radical scavenging activity. Results represent the mean $\operatorname{SD}(n=3)$ and*on the bars denote the significant difference within the plants $(\mathrm{P} \leq 0.05)$

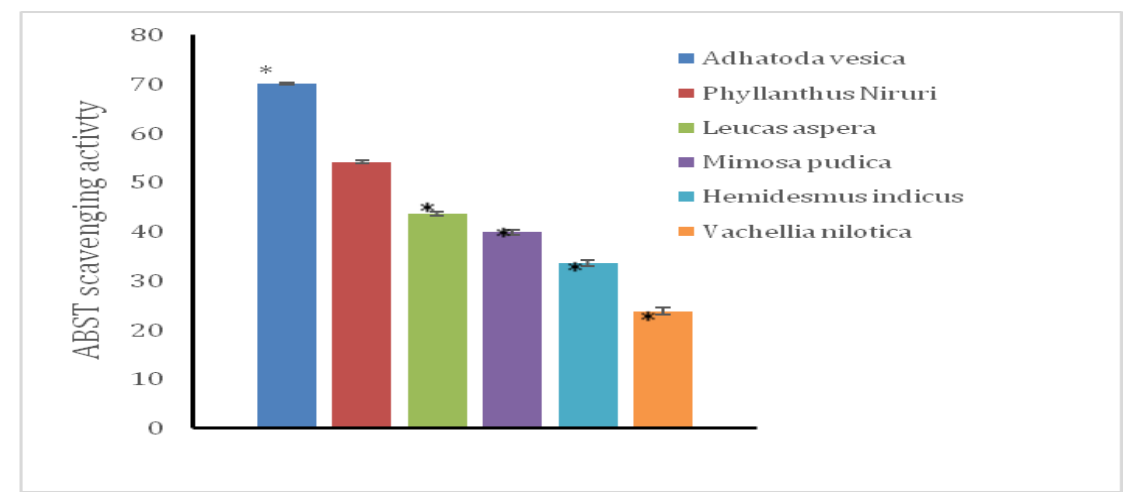

Similarly the data taken together demonstrated that the flavonoids in case of Phyllanthus niruri was higher $(57.7 \mathrm{mg}$ QE per g) in comparison to Mimosa pudica (49.47mg QE per g), (47.57mg QE per g), Vachellia nilotica (43.6mg QE per g), Adhatoda vesica (39.4 mg QE per g) and Hemidesmus indicus (35.1mg QE per g) (Fig. $1 b)$.

Furthermore, the radical scavenging potential of the plants were analysed. The optical densities of different plant extracts were then used to calculate the antioxidant potential of the same. The results showed that Adhatoda vesica could scavenge $56.6 \%$ of radical whereas Phylanthus niruri and other plant extract Leucas aspera, Mimosa pudica, Hemidesmus indicus and Vachellia nilotica showed $45.7 \%, 43.7 \%, 37.6 \%, 29.6 \%$ and $23.9 \%$ scavenging potential as illustrated (Fig. 2).

The principle behind the nitric oxide scavenging activity is based on the inhibition of nitric oxide competing with oxygen leading to reduction of nitric ions. Nitric oxide as ROS is associated with various pathological condition such as inflammation, cancer and other diseases (Islam et al., 2018). In the present study all the plant extract showed scavenging activity in following order; AV:
66.4\%, PN: 53.7\%, LA: 51.6\%, MP: $38.9 \%$, HI: $45.2 \%$ and VN: $32.3 \%$ (Fig. 3).

Similarly results from ABTS free radical scavenging assay showed a similar pattern of scavenging activity in which Adhatoda vesica plant extract showed highest scavenging action of $70.1 \%$ followed by PN: $54.2 \%>$ LA: 40.5\%>MP: $39.9 \%>\mathrm{HI}: 33.6 \%>\mathrm{VN}: 23.3 \%$ (Fig. 4).

The statistical analysis of the data obtained from the various mentioned parameters revealed significant difference in TPC and TFC. Moreover, DPPH, ABTS and NO scavenging potential of the various plant showed significant difference at $\mathrm{p} \leq 0.05$

In conclusion the phytochemical constituents play a central role in providing a plant its antioxidant properties. The total phenolic content and flavonoid content of the plants is responsible for antioxidant potential of Adhatoda vesica and Phyllanthus niruri which makes them more potent antioxidant scavenger, whereas the other plant as per their phytochemical composition showed different levels of antioxidant potential. Thus, from comparison of the mentioned plants, it could be concluded that Adhatoda vesica and phyllanthus niruri possess more antioxidant potential compared to Leucas aspera, Mimosa 
pudica, Hemidesmus indicus and Vachellia nilotica.

\section{References}

Ahmad, H., Sehgal, S, Mishra, A and Gupta, R.2012. Mimosa pudica L. (Laajvanti): an overview. Pharmacognosy reviews. 6(12): 115.

Aneja, V., Suthar, A., Verma, S and Kalkunte, S. 2008. Phyto-pharmacology of Hemidesmus indicus. Pharmacognosy Reviews. 2(3): 143.

Atoui, A. K., Mansouri, A., Boskou, G and Kefalas, P. 2005. Tea and herbal infusions: their antioxidant activity and phenolic profile. Food chemistry. 89(1): 27-36.

Chew, A. L., Jessica, J. J. A and Sasidharan, S. 2012. Antioxidant and antibacterial activity of different parts of Leucas aspera. Asian Pacific Journal of Tropical Biomedicine. 2(3): 176-180.

Dandekar, S. P., Bajpai, N. D and Sakharwade, S. N. A Multifunctional Hemidesmus indicus As Cosmetic Agent: A Review Article.

Das, S., Naik, P and Panda,P. 2017. Effect of Hemidesmus indicus $\mathrm{R}$. Br. root extract on urinary tract infection causing bacteria. Int $\mathbf{J}$ Herbal Med. 5(5): 160-168.

Ezzat, M. I., Okba, M. M., Ahmed, S. H., ElBanna, H. A., Prince, A., Mohamed, S. O and Ezzat, S. M. 2020. In-depth hepatoprotective mechanistic study of Phyllanthus niruri: In vitro and in vivo studies and its chemical characterization. PloS one. 15(1): e0226185.

Goudgaon, N. M., Basavaraj, N. R and Vijayalaxmi, A. 2003. Antiinflammatory activity of different fractions of Leucas aspera Spreng. Indian Journal of Pharmacology. 35(6): 397.
Gupta, Y. K., and Peshin, S. S. 2012. Do herbal medicines have potential for managing snake bite envenomation? Toxicology international. 19(2): 89.

Islam, S. N., Farooq, S., and Sehgal, A. (2018). Effect of consecutive steeping on antioxidant potential of green, oolong and black tea. International Journal of Food Science and Technology, 53(1), 182-187.

Jayakumar, K., SatheesKannan, T. M and Vijayarengan, P. 2015. Leucas aspera L.-Medicinal Herb. Int J Trad Nat Med, 5, 1-5.

Joseph, B., and Raj, S. J. 2011. An overview: pharmacognostic properties of Phyllanthus amarus Linn. Int $\mathrm{J}$ Pharmacol. 7(1): 40-45.

Joseph, B., George, J and Mohan, J. 2013. Pharmacology and traditional uses of Mimosa pudica. International journal of pharmaceutical sciences and drug research. 5(2): 41-44.

Keerthi Kanimozhi, K. 2017. Evaluation of anti-arthritic activity of the ethanolic extract of Mimosa pudica Linn. in Complete Freund's Adjuvant Induced Arthritis in Wistar Rats (Doctoral dissertation, CL Baid Metha College of Pharmacy, Chennai).

Kim, D.O., Lee, K.W., Lee, H.J. and Lee, C.Y. (2002). Vitamin Cequivalent antioxidant capacity (VCAEAC) of Phenolic phyto-chemical. Journal of Agriculture Food Chemistry,50, 3713-3717.

Mahanta, M., and Mukherjee, A. K. 2001. Neutralisation of lethality, myotoxicity and toxic enzymes of Naja kaouthia venom by Mimosa pudica root extracts. Journal of Ethnopharmacology. 75(1): 55-60.

Mallick, C.P. and Singh, M.B. (1980).Plant enzymology and Histoen-zymology. P. 286 New Delhi: Kalyani Publishers

Manisha, K. Anti-Tuberculosis Activity Of 
Selected Medicinal Plants: A Review.

Miller, J. H., Chambliss, E. B and Loewenstein, N. J. 2012. Invasive plants in southern forests. Southern Research Station, Asheville, NC.

Naik, A. D., and Juvekar, A. R. 2003. Effects of alkaloidal extract of Phyllanthus niruri on HIV replication. Indian journal of medical sciences. 57(9): 387-393.

Pansare, T. A., Khandekar, S. B and Satpudke, S. S. 2018. Ayurvedic and modern aspects of Sariva (Hemidesmus indicus R. Br): An overview. Int $\mathrm{J}$ Ayurvedic Herbal Med. 8(1): 3133-3143.

Patro, G., Bhattamisra, S. K. and Mohanty, B. K. 2016. Effects of Mimosa pudica L. leaves extract on anxiety, depression and memory. Avicenna journal of phytomedicine. 6(6): 696.

Prajapati, M. S., Patel, J. B., Modi, K and Shah, M. B. 2010. Leucas aspera: A review. Pharmacognosy reviews. 4(7): 85.

Rahman, M. A., and Islam, M. S. 2013. Antioxidant, antibacterial and cytotoxic effects of the phytochemicals of whole Leucas aspera extract. Asian Pacific journal of tropical biomedicine. 3(4): 273.

Rao, M. N. A. 1997. Nitric oxide scavenging by curcuminoids. Journal of pharmacy and Pharmacology, 49(1):105-107.

Re, R., Pellegrini, N., Proteggente, A., Pannala, A., Yang, M. and RiceEvans, C. (1999). Antioxidant activity applying an improved ABTS radical cation decolorization assay. Free Radical Biology and Medicine, 26, 1231-1237.

Sheeba, B. J., and Mohan, T. S. 2012. Antimicrobial activity of Adhatoda vasica against clinical pathogens. Asian J Plant Sci Res. 2(2): 83-88.

Shirwaikar, A., Prabhu, K. S., and Punitha, I. S. R. 2006. In vitro antioxidant studies of Sphaeranthus indicus (Linn).

Singh, S., 2015. Ethno botanical study of some wild herb species Parsa District Forest of Nepal. Journal of Pharmacognosy and Phytochemistry. 4(1).

Varnika, S., Ashish, S and Imran, A. 2012. A review on ethnomedical and traditional uses of Mimosa pudica (Chui-mui). Int. Res. J. Pharm. 3(2): 41-44.

\section{How to cite this article:}

Srishti Prashar, Parminder Kaur, Prakriti Sharma, Arshida Khatun and Shaikh I. Nasrul. 2020. A Study on Comparative Antioxidant Properties of Mimosa pudica, Vachellia nilotica, Leucas aspera, Phyllanthus niruri, Emidesmus indicus and Adhatoda vasica. Int.J.Curr.Microbiol.App.Sci. 9(12): 833-840. doi: https://doi.org/10.20546/ijcmas.2020.912.100 